\title{
Utilisation of Skilled Delivery in Ghana: A Systematic Review
}

\author{
Alex Darteh Afrifa*, James Kojo Prah, Kwasi Sobre Nkrumah \\ University of Cape Coast \\ *Corresponding author email: alex.afrifa@ucc.edu.gh
}

Received: 12 October 2021 / Accepted: 06 December 2021 / Published: 07 December 2021

\begin{abstract}
Background: Access to a doctor, nurse, or a midwife during childbirth is key to the global effort to reduce maternal mortality ratios. Ghana has recorded significant improvements in maternal care over the past three decades. However, despite many policies aimed at improving health care for pregnant women such as the free maternal care policy, many Ghanaian women still deliver without a skilled birth attendant present. This systematic review, therefore, sought to identify the various factors affecting utilisation of skilled birth attendance in Ghana.

Methods: PubMed Central, African Journals Online (AJOL), CINAHL Plus with Full Text (EBSCO), and Science Direct were searched for studies from January 2010 to December 2020. A broad range of search terms was used. Studies included had diverse designs, were conducted among Ghanaian pregnant women, and had skilled delivery as an outcome of interest. The quality of studies was assessed. Due to the diversity of types of studies included in this systematic review (including qualitative, descriptive, and evaluative studies that ranged from simple bivariate analyses to complex multivariate modelling), a meta-analysis was neither possible nor appropriate. We, therefore, conducted a narrative synthesis of the search findings.

Results: Twenty-four (24) studies met our inclusion criteria for this review. Included studies comprised sixteen (16) cross-sectional studies and eight (8) qualitative studies. The sample size of the included studies cumulatively was 86,998 participants. The emerging themes were: health system factors (10); maternal and family factors (5); and sociodemographic factors (9).

Conclusion: In general, health system factors; maternal and family factors; and sociodemographic factors were found to influence skilled delivery services in Ghana. Therefore, in order to ensure that there is a skilled birth attendant present at every birth, efforts should aim at addressing social and cultural factors which have been identified as key determinants to utilisation of skilled delivery in Ghana.
\end{abstract}

Keywords: Skilled birth attendance; Skilled delivery; Health facility delivery.

\section{Introduction}

About 830 women die from pregnancy or childbirth-related complications around the world each day with most of the deaths occurring in low-resource settings. It was estimated in 2015 that roughly 303,000 women died during and following pregnancy and childbirth (Alkema et al., 2016). Most obstetric complications were preventable or manageable if the women had access to a doctor, a nurse, or a midwife during childbirth. Globally, though coverage of Skilled Birth attendant (SBA) during childbirth increased from 61\% in 2000 to 78\% in 2016 (World Health Organization \& The World Bank, 2015), yet millions of births were not assisted by SBA despite steady global and within-regions improvements. Ironically, World Health Organization (2016) estimated that approximately only half or less of all live births were delivered with the assistance of SBA in sub-Saharan Africa in 2016. This was stressed by a study that analysed the Demographic and Health Surveys (DHS) from 34 sub-Saharan African countries involving 72,772 women having their first birth in the 5 years preceding the surveys. In that review, Dunlop, Benova, and Campbell (2018) found that 59.9\% of the women had a facility-based delivery for their first birth - ranging from $19.4 \%$ in Chad to $96.6 \%$ in Rwanda. 
Maternal mortality has been described as deaths due to complications from pregnancy or childbirth (World Health Organization, 2019). The United Nations inter-agency (United Nations Children's Fund (UNICEF), United Nations Population Fund (UNFPA), World Bank Group, and the United Nations Population Division) estimates that global Maternal Mortality Ratio (MMR) declined by 38\% between 2000 and 2017, that is, 342 to 211 deaths per 100,000 live births. This translates into an average annual rate of reduction of $2.9 \%$. Though there has been significant progress since the year 2000, South Asia achieved the greatest overall percentage reduction in MMR, with a reduction of 59\% (from 395 to 163 maternal deaths per 100,000 live births) and Sub-Saharan Africa achieved a substantial reduction of 39\% of maternal mortality during this period. Though appreciative, this is less than half of the $6.4 \%$ annual rate required to achieve the Sustainable Development Global (SDG) goal of achieving less than 70 maternal deaths per 100,000 live births (World Health Organization, 2015).

The WHO, the International Confederation of Midwives (ICM), and the International Federation of Gynaecology and Obstetrics (FIGO) in a consensus statement described a Skilled Birth Attendant (SBA) as:

"an accredited health professional such as a midwife, a doctor or a nurse who has been educated and trained and equipped with the skills needed in the management of uncomplicated pregnancies, childbirth and the immediate postnatal periods, and in the identification, management and referral of complications in women and new-borns"

(World Health Organization, 2004).

Skilled attendance is therefore the process by which a woman is provided with adequate care during labour, delivery and the early postpartum period which is widely accepted as the single most important factor in preventing maternal deaths (World Health Organization, 1999). The proportion of births attended by skilled health personnel can thus be measured as the percentage of live births attended by skilled health personnel (doctor, nurse, midwife).

SBA services are characterized by two criteria: (1) the attendant, and (2) the environment (Hussein et al., 2004). The attendant who has been trained to manage normal deliveries and refer complications must be present during labour, delivery and postpartum. Secondly, the environment must be enabling, such that the labouring woman has the support necessary to access a sufficiently equipped Health Care Facility (HCF) as needed. In low-income countries however, the scarcity of resources often means HCF delivery is a necessary condition for SBA (Bell et al., 2003). This goes on to emphasise the fact that the process of skilled delivery requires a skilled attendant and an enabling environment (including political and policy context in which the attendant operates), adequate supplies, equipment, infrastructure, and a well efficient and effective systems of communication and referral. The attendance must be within a favourable socio-cultural environment, whilst more proximate factors such as pre- and in-service training, supervision, deployment, and adequate health systems financing is ensured. In the absence of SBA or as a matter of choice, some pregnant women would access a Traditional Birth Attendant (TBA). A TBA has been described as a person who assists the mother during childbirth and initially acquired her skills by delivering babies herself or through apprenticeship to other TBAs (WHO/UNFPA/UNICEF, 1992).

Ghana has experienced a steady decline in maternal deaths over the past 30 years. The maternal mortality ratio in Ghana was 760 per 100000 live births in 1990, 380 in 2013 (World Health Organization, 2014), 319 in 2015 and 310 per 100000 live births in 2017 (Ghana Statistical Service, Ghana Health Service, ICF International, 2018). Even though this achievement is commendable, it is far below than the global target of 70 deaths per 100000 live births by 2030. Factors known to contribute to maternal deaths includes antenatal clinic attendance, delivery at health facilities and the presence of skilled heath workers at birth. Between 1988 and 2018, Ghana chalked significant successes in the areas of antenatal care by skilled providers, health facility deliveries and births with skilled attendants present (figure 1). For example, births with skilled providers present increased from 42\% in 1993 to 79\% in 2018 (Ghana Statistical Service, 2016; Multiple Indicator Survey, 2019). Until all Ghanaian women are able to access skilled deliveries, achieving the SDG 3 target for maternal deaths will remain a dream that cannot be realized. It is therefore important 
Utilisation Of Skilled Delivery in Ghana: A Systematic Review

to determine the factors affecting utilisation of skilled deliveries in Ghana especially in the context of the current provision of free maternal health care.

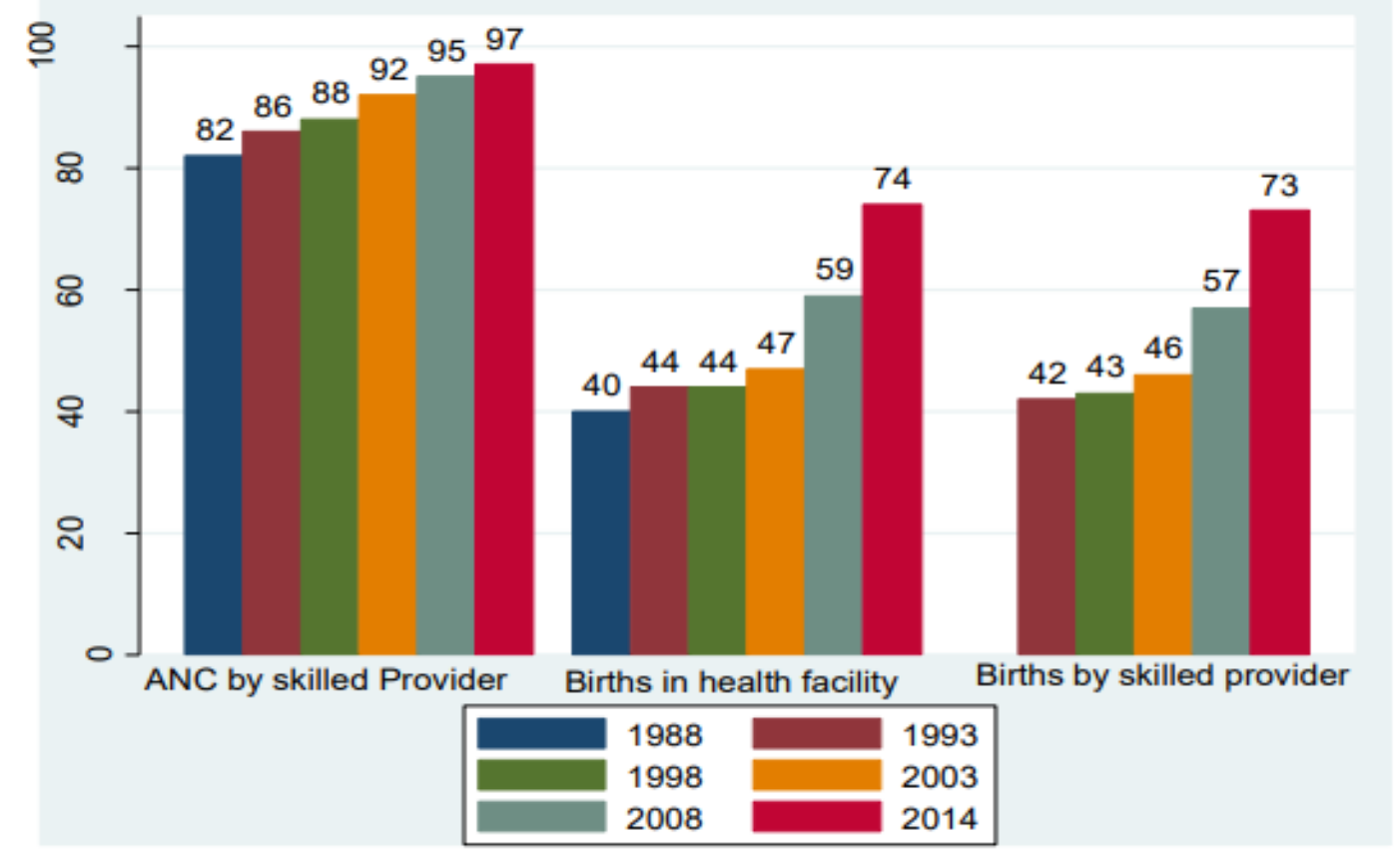

Figure 1: Trends of maternal care from 1998 to 2014 (Ghana Statistical Service, 2016)

The objective of this review was therefore to find, analyse and discuss the many factors that affect the utilisation of skilled delivery among pregnant women in Ghana.

\section{Materials and Methods}

\subsection{Search strategy}

A systematic search of peer-reviewed published literature was done on 02/06/21. Using the phrase "utilisation of skilled delivery in Ghana" in PubMed Central, African Journals Online (AJOL), CINAHL Plus with Full Text (EBSCO), and Science Direct (Table 1).

Table 1: Sources of Studies

\begin{tabular}{lllll}
\hline Database & $\begin{array}{l}\text { Search } \\
\text { results }\end{array}$ & $\begin{array}{l}\text { After title } \\
\text { screening }\end{array}$ & $\begin{array}{l}\text { After abstract } \\
\text { screening }\end{array}$ & $\begin{array}{l}\text { After removal of } \\
\text { duplicates }\end{array}$ \\
\hline PubMed Central & 865 & 39 & 29 & 19 \\
CINAHL & 6 & 5 & 5 & 1 \\
Science Direct & 142 & 83 & 61 & 1 \\
$\begin{array}{l}\text { African Journals Online } \\
\text { (AJOL) }\end{array}$ & 197 & 60 & 4 & 3 \\
Total & $\mathbf{1 , 2 1 0}$ & $\mathbf{1 8 7}$ & $\mathbf{9 9}$ & $\mathbf{2 4}$ \\
\hline
\end{tabular}

Date range: 01/01/2010 to 31/12/2020 (Appendix 2). Inclusion criteria: the study setting must be in Ghana, population must be pregnant women, and outcome of interest must be health facility or skilled delivery. Exclusion criteria: studies were excluded if the focus was on antenatal care, if it was a study protocol or a review article, and, if study language was not English.

\subsection{Study selection and data extraction}

Studies were included in the review if they were published in a peer-reviewed journal in English between January 2010 and December 2020, were conducted entirely in Ghana, reported on the results of original research, and included a primary outcome variable of delivery location, or SBA, articles needed to address 
Afrifa et al., Extsv. Rev.; Vol. 1, Issue 1, pp: 30-38, 2021

determinants, predictors, or factors associated with delivery location. Review articles were excluded (Figure 2).

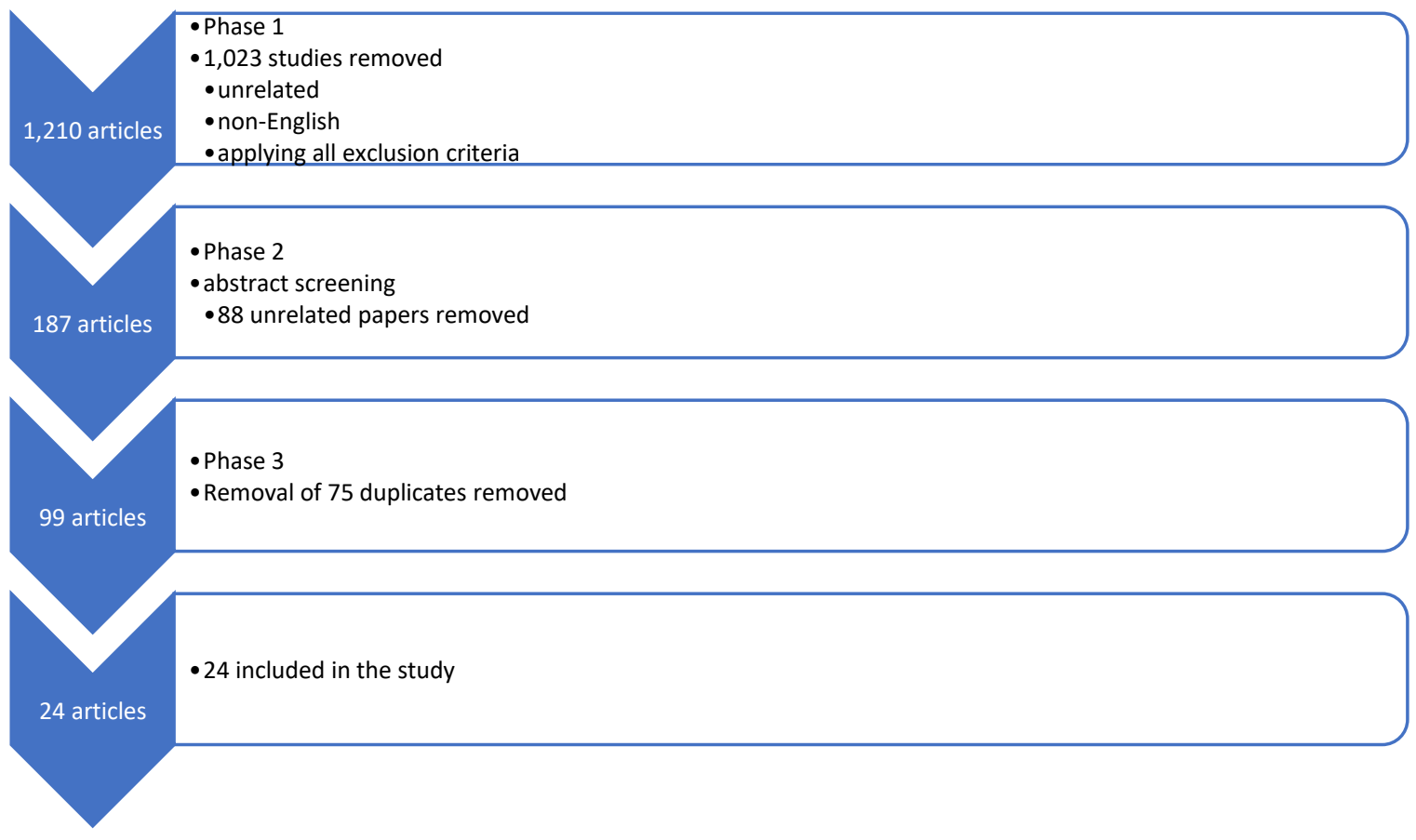

Figure 2: Process for selection of articles for analysis

\subsection{Analysis and synthesis strategy}

Due to the diversity of types of studies included in this systematic review (including qualitative, descriptive and evaluative studies that ranged from simple bivariate analyses to complex multivariate modelling), a meta-analysis was neither possible nor appropriate. A matrix-type table was created with Microsoft Excel to group relevant aspects of included studies (like: author(s), date, title, method, population and sample, study location, findings, and conclusions). Studies were grouped and colour-coded depending on the study's focus and objectives. Themes (health system factors, sociodemographic factors, and maternal and family factors) thus emerged from this point.

\section{Findings}

The yield from the search was 1,210 articles. After careful review of the titles (and where doubtful, abstract and/or full article), removal of duplicates, and applying the inclusion and exclusion criteria, twenty-four (24) studies were selected for this review (Appendix 1). The included studies comprised sixteen (16) cross sectional studies and eight (8) qualitative studies. The sample size of the included studies cumulatively was 86,998 participants. The emerging themes were: health system factors (10); maternal and family factors (5); and sociodemographic factors (9) (Table 2). These themes together with subthemes from the systematic literature search forms the basis for discussion in this paper.

Table 2: Emerging themes

\begin{tabular}{ll}
\hline Theme & Number of Articles \\
\hline Health system factors & 10 \\
Maternal and family factors & 5 \\
Sociodemographic factors & 9 \\
\hline TOTAL & 24 \\
\hline
\end{tabular}




\section{Discussion}

This review sought to analyse and discuss the many factors that affect the utilisation of skilled delivery among pregnant women in Ghana. The themes that emerged from the search and synthesis of studies were (1) health system factors, (2) maternal and family factors, and (3) sociodemographic factors that influences skilled delivery services.

\subsection{Health system factors}

For effective healthcare leadership and governance, the WHO suggests ensuring that strategic policy frameworks exist and combined with effective oversight, building of coalitions, regulation, attention to design of health systems and accountability. In this, the state or government, the health service providers, and medical and non-medical health staff are the three main categories of stakeholders who interact with each other to determine the health system and its governance (World Health Organisation, n.d.). The World Health Organization (2010) again noted that though sufficient funding is essential to achieve universal health coverage, it will be difficult to get close to universal coverage if people have problems accessing the services because they have to pay for services upfront. It was further noted that almost all countries impose some form of out-of-pocket payment for health service (also called cost-sharing) although the poorer the country, the higher the proportion of total spending that is financed in this way.

Among the several health system factors that determine whether or not the woman delivers with a SBA in Ghana are: ANC attendance (Manyeh et al., 2017; Saaka \& Akuamoah-Boateng, 2020); NHIS membership (Gudu \& Addo, 2017); distance to a healthcare facility (Atinga, Baku, \& Adongo, 2014); and fee-exemption or free delivery (Asante-Sarpong, Owusu, Saravanan, Appiah, \& Abu, 2016).

The Government of Ghana through the Ministry of Health and related agencies have over the years attempted to improve access to health services through some policies, among them are the free-delivery initiative and the NHIS scheme.

Asante-Sarpong et al. (2016) found that the free maternal health policy did not guarantee utilization of skilled deliveries in the Central Region off Ghana. Their study revealed that a high universal awareness of the policy (97.3\%) did not reflect in the utilization of SBA at birth (65\%). Factors such as age of mother, parity and geographical area of residence, whether urban or rural affected the use of skilled deliveries even if maternal health care is free. This implies that other health system problems apart from cost could affect utilization of skilled deliveries by pregnant women. Whilst Browne et al. (2016) asserted that maternal health insurance status plays a significant role in the acceptance of the maternal, neonatal and child health continuum of care service, Khan and Singh (2016) maintains that though health insurance eliminates the monetary barrier, it does not solve health services accessibility problems and prevalent geographic disparities in coverage of SBA. To examine the influence of four (4) maternity fee paying policies enacted in Ghana over three decades, (Amoakoh-Coleman et al., 2015) analysed two decades of birth histories data and found that at the country-level policies had a positive influence on use of skilled delivery care, yet their impacts on reducing between-district inequalities were trivial.

Despite the woman's intentions to deliver or not to deliver in a HCF, access or distance or proximity to the HCF is significant. In Dotse-Gborgbortsi et al. (2020), a spatial interaction model (a model that predicts movement from one place to another) revealed that each kilometre increase in distance significantly reduced the rate of women giving birth in HCFs by 6.7\%. Other studies (Atinga, Baku, \& Adongo, 2014; Saaka \& Akuamoah-Boateng, 2020) also found proximity to a HCF to influence utilisation of skilled delivery.

Though ANC usage was high (97\%) according to the 2014 Ghana Demographic and Health Survey, it did not translate into the utilization of skilled delivery (which was 73\%) over the same period (Ghana Statistical Service, Ghana Health Service, and I C F International, 2015).

Some studies found similar results from different localities. Saaka and Akuamoah-Boateng (2020), recently found a little over $68 \%$ of pregnant women were assisted by skilled person at delivery though over $98 \%$ of them had receive ANC during pregnancy. The authors found proximity to a health facility and higher 
Afrifa et al., Extsv. Rev.; Vol. 1, Issue 1, pp: 30-38, 2021

educational level of the woman to be contributors to health facility delivery, this was corroborated by Atinga, Baku, and Adongo (2014) who also found health facility delivery to be high for women aged between 35 and 39 years, women with at least junior high education, living close to the health facility, and women in their second and third trimester. Similarly, Ganle, Kombet, and Baatiema (2019) studied 322 postpartum women who delivered between January and December 2016. ANC attendance among respondents was very high $90.4 \%(\mathrm{n}=291)$, yet the prevalence of supervised delivery was merely $68 \%$ $(\mathrm{n}=219)$. Also, Gudu and Addo (2017) studied 400 women between the ages of 15 and 49 years who had given birth one year prior to the study and found that out of the 400 women included in the analysis, $93.3 \%$ delivered in a health facility. A little over $97 \%$ attended or received ANC at their last pregnancy with $75 \%$ of them attending four or more ANC clinic. Out of the over 97\% who attended ANC, $91.5 \%$ utilized skilled delivery services.

\subsection{Maternal and family factors}

In developing countries, the decision on place of delivery is mostly not only the privilege of women but made by several actors and factors, some of which are beyond the responsibility of women. Thus augmenting empowerment status of women in developing countries is one of the recognised methods to improving maternal healthcare service utilisation (Lozano et al., 2011). The United Nations Human Rights (UNHR) agency notes that:

"the right of a woman or girl to make autonomous decisions about her own body and reproductive functions is at the very core of her fundamental right to equality and privacy, concerning intimate matters of physical and psychological integrity"

(United Nations Human Rights, 2017)

Though the pregnant woman may have the will to deliver with a SBA, certain factors promote either positively or negatively their decision to do so. Among the many factors are:

1. Positive promoters: community/network support (Cofie et al., 2018; Crissman et al., 2013b); the knowledge of their partner about health facility delivery and the need for support persons during hospitalisation; decision-making autonomy of the woman; household wealth (Amu \& Sekyi, 2018); and partner involvement (Saah et al., 2019).

2. Negative promoters: maltreatment by midwives (leading to bad past experience); cost of delivery and transportation to the health facility (compounded by household wealth), precipitous labour and possible complications during delivery (Crissman et al., 2013); negative interactions with SBA; lack of confidence in SBA's abilities; and SBA disrespecting traditional beliefs of the woman (Adatara, Strumpher, \& Ricks, 2019).

\subsection{Sociodemographic factors}

Sociodemographic factors refer to a combination of social and demographic dynamics that describe people in a definite group or population. In this study, several sociodemographic factors influencing SBA access emerged. Among the sociodemographic factors found during the analysis are: education of the woman (Asamoah, Agardh, Pettersson, \& Östergren, 2014; Dickson, Adde, \& Amu, 2016); age of the woman (3539 years) (Atinga, Baku, \& Adongo, 2014); ethnicity and education of husband (Sakeah et al., 2014); religion of the woman (Ganle, 2015). A study by Ganle (2015), with the aim to explore the maternity healthcare needs and care experiences of Muslim women and the barriers to accessing and utilising the services in three communities in the Northern Region (NR) of Ghana, recruited 94 Muslim women and found that the women do want to receive skilled care in a HCF but they often experience problems with accessing and using such services. These difficulties were often as a result of a religious obligation to maintain bodily sanctity through modest dressing and to avoid unauthorised bodily exposure or contact with male or alien caregivers. Other related access barriers include lack of privacy, healthcare providers' insensitivity and lack of knowledge about Muslim women's religious and cultural practices, and health information that lacked the cultural and religious specificity to meet Muslim women's maternity care needs. 


\section{Conclusion}

This study analysed and discussed the factors that affect the utilisation of skilled delivery among pregnant women in Ghana (either positively or negatively). Grossly, health system factors, maternal and family factors, and sociodemographic factors were found to influence skilled delivery services in Ghana. Though the Government of Ghana through its various health-focused agencies have over the years attempted to improve access to SBA by providing avenues for either free delivery services or reimburse service providers in the form of NHIS, delivery in a health facility has not improved appreciably thus calling for a renewed energy to improve utilization of SBA and thus reducing the high maternal mortality ratio in Ghana. These efforts should employ the human rights approach that will pay more attention to social and cultural factors such as the autonomy of women and empowerment of women especially economically. This will allow pregnant women to take decisions to seek health care and have the financial capacity to seek skilled deliveries at all times without being overly reliant on partners and family members who may not be supportive.

\section{Competing Interests}

The authors declared that they do not have any conflict of interest in publishing this work.

\section{How to Cite this Article:}

Will be updated in the final version.

\section{References}

Adatara, P., Strumpher, J., \& Ricks, E. (2019). A qualitative study on rural women's experiences relating to the utilisation of birth care provided by skilled birth attendants in the rural areas of Bongo District in the Upper East Region of Ghana. BMC Pregnancy and Childbirth, 19(1), 1-8. https://doi.org/10.1186/s12884-019-2337-0

Alkema, L., Chou, D., Hogan, D., Zhang, S., Moller, A. B., Gemmill, A., Fat, D. M., Boerma, T., Temmerman, M., Mathers, C., \& Say, L. (2016). Global, regional, and national levels and trends in maternal mortality between 1990 and 2015, with scenario-based projections to 2030: A systematic analysis by the un Maternal Mortality Estimation Inter-Agency Group. The Lancet, 387(10017), 462-474. https://doi.org/10.1016/S0140-6736(15)00838-7

Amoakoh-Coleman, M., Ansah, E. K., Agyepong, I. A., Grobbee, D. E., Kayode, G. A., \& Klipstein-Grobusch, K. (2015). Predictors of skilled attendance at delivery among antenatal clinic attendants in Ghana: A cross-sectional study of population data. BMJ Open, 5(5), e007810-e007810. https://doi.org/10.1136/bmjopen-2015-007810

Amu, H. \& Sekyi, D. K. (2018). Effects of Spatial Location and Household Wealth on the Utilisation of Skilled Delivery Attendants at Delivery Among Women in Rural Ghana. Ghana Journal of Geography, 10(1), 58-77. https://doi.org/https://dx.doi.org/10.4314/gjg.v10i1.4

Asamoah, B. O., Agardh, A., Pettersson, K. O., \& Östergren, P. O. (2014). Magnitude and trends of inequalities in antenatal care and delivery under skilled care among different socio-demographic groups in Ghana from 1988 - 2008. BMC Pregnancy and Childbirth, 14(1). https://doi.org/10.1186/1471-2393-14-295

Asante-Sarpong, H., Owusu, A. Y., Saravanan, S., Appiah, E., \& Abu, M. (2016). Determinants of use of supervised delivery care under Ghana's fee exemption policy for maternal healthcare: The case of the Central Region. BMC Pregnancy and Childbirth, 16(1), 1-10. https://doi.org/10.1186/s12884-016-0960-6

Atinga, R. A., Baku, A. A. \& Adongo, P. B. (2014). Drivers of Prenatal Care Quality and Uptake of Supervised Delivery Services in Ghana. Annals of Medical and Health Sciences Research, 4(3), 264-271.

Atinga, R., Baku, A., \& Adongo, P. (2014). Drivers of prenatal care quality and uptake of supervised delivery services in ghana. Annals of Medical and Health Sciences Research, 4(Suppl 3), S264-71. https://doi.org/10.4103/2141-9248.141970

Bell, J., Hussein, J., Jentsch, B., Scotland, G., Bullough, C., \& Graham, W. (2003). Improving Skilled Attendance at Delivery : A Preliminary Report of the SAFE Strategy Development Tool. Birth, 30(4), 227-234. https://doi.org/https://doi.org/10.1046/j.1523536X.2003.00252.x

Browne, J. L., Kayode, G. A., Arhinful, D., Fidder, S. A. J. J., Grobbee, D. E., \& Klipstein-Grobusch, K. (2016). Health insurance determines antenatal, delivery and postnatal care utilisation: Evidence from the Ghana Demographic and Health Surveillance data. BMJ Open, 6(3). https://doi.org/10.1136/bmjopen-2015-008175

Cofie, L. E., Barrington, C., Sodzi-Tettey, S., Ennett, S., Maman, S., \& Singh, K. (2018). A qualitative study of women's network social support and facility delivery in rural Ghana. PLoS ONE, 13(11), 1-15. https://doi.org/10.1371/journal.pone.0206429

Crissman, H. P., Engmann, C. E., Adanu, R. M., Nimako, D., Crespo, K., \& Moyer, C. A. (2013). Shifting norms: pregnant women's perspectives on skilled birth attendance and facility-based delivery in rural Ghana. African Journal of Reproductive Health, 17(1), 1526.

Dickson, K. S., Adde, K. S. \& Amu, H. (2016). What Influences Where They Give Birth? Determinants of Place of Delivery among Women in Rural Ghana. International Journal of Reproductive Medicine, 2016, 1-8. https://doi.org/10.1155/2016/7203980

Dotse-Gborgbortsi, W., Dwomoh, D., Alegana, V., Hill, A., Tatem, A. J., \& Wright, J. (2020). The influence of distance and quality on utilisation of birthing services at health facilities in Eastern Region, Ghana. BMJ Global Health, 4. https://doi.org/10.1136/bmjgh-2019002020 
Afrifa et al., Extsv. Rev.; Vol. 1, Issue 1, pp: 30-38, 2021

Dunlop, C. L., Benova, L., \& Campbell, O. (2018). Effect of maternal age on facility-based delivery: Analysis of first-order births in 34 countries of sub-Saharan Africa using demographic and health survey data. BMJ Open, 8(4), 1-9. https://doi.org/10.1136/bmjopen2017-020231

Ganle, J. K. (2015). Why Muslim women in Northern Ghana do not use skilled maternal healthcare services at health facilities: a qualitative study. BMC International Health and Human Rights, 15(1), 10. https://doi.org/10.1186/s12914-015-0048-9

Ganle, John Kuumuori, Kombet, M. L., \& Baatiema, L. (2019). Factors influencing the use of supervised delivery services in Garu-Tempane District, Ghana. BMC Pregnancy and Childbirth, 19(1), 1-11. https://doi.org/10.1186/s12884-019-2295-6

Ghana Statistical Service, Ghana Health Service, and I. C. F. I. (2015). Ghana Demographic and Health Survey. Demographic and Health Survey 2014. Rockville, Maryland, USA. Retrieved from https://dhsprogram.com/pubs/pdf/FR307/FR307.pdf

Ghana Statistical Service, Ghana Health Service, and I. I. (2018). Ghana Maternal Health Survey 2017: Key Indicators Report. Accra, Ghana.

Gudu, W., \& Addo, B. (2017). Factors associated with utilization of skilled service delivery among women in rural Northern Ghana: A cross sectional study. BMC Pregnancy and Childbirth, 17(1), 159. https://doi.org/10.1186/s12884-017-1344-2

Hussein, J., Bell, J., Nazzar, A., Abbey, M., Adjei, S., \& Graham, W. (2004). The skilled attendance index: Proposal for a new measure of skilled attendance at delivery. Reproductive Health Matters, 12(24), 160-170. https://doi.org/10.1016/S0968-8080(04)24136-2

Khan, S. M., \& Singh, K. (2016). The Association Between Health Insurance Coverage and Skilled Birth Attendance in Ghana: A National Study. Maternal and Child Health Journal, 20(3), 534-541. https://doi.org/10.1007/s10995-015-1851-6

Lozano, R., Wang, H., Foreman, K. J., Rajaratnam, J. K., Naghavi, M., Marcus, J. R., ... Murray, C. J. (2011). Progress towards Millennium Development Goals 4 and 5 on maternal and child mortality: an updated systematic analysis. The Lancet, 378(9797), 1139-1165. https://doi.org/10.1016/S0140-6736(11)61337-8

Manyeh, A. K., Akpakli, D. E., Kukula, V., Ekey, R. A., Narh-Bana, S., Adjei, A., \& Gyapong, M. (2017). Socio-demographic determinants of skilled birth attendant at delivery in rural southern Ghana. BMC Research Notes, 10(1), 1-7. https://doi.org/10.1186/s13104-0172591-z

Saah, F. I., Tarkang, E. E., Komesuor, J., Osei, E., Acquah, E., \& Amu, H. (2019). Involvement of Male Partners in Skilled Birth Care in the North Dayi District, Ghana. International Journal of Reproductive Medicine, 2019, 1-12. https://doi.org/10.1155/2019/2852861

Saaka, M., \& Akuamoah-Boateng, J. (2020). Prevalence and Determinants of Rural-Urban Utilization of Skilled Delivery Services in Northern Ghana. Scientifica, 2020. https://doi.org/10.1155/2020/9373476

Sakeah, E., Doctor, H. V., McCloskey, L., Bernstein, J., Yeboah-Antwi, K., \& Mills, S. (2014). Using the community-based health planning and services program to promote skilled delivery in rural Ghana: Socio-demographic factors that influence women utilization of skilled attendants at birth in Northern Ghana. BMC Public Health, 14(1). https://doi.org/10.1186/1471-2458-14-344

United Nations Human Rights. (2017). Women's Autonomy, Equality and Reproductive Health in International Human Rights: Between Recognition, Backlash Regressive Trends. Retrieved https://www.ohchr.org/Documents/Issues/Women/WG/WomensAutonomyEqualityReproductiveHealth.pdf

WHO/UNFPA/UNICEF. (1992). Traditional Birth Attendants: a joint WHO/UNFPA/UNICEF statement. WHO Offset Publ (Geneva). Geneva, Switzerland: World Health Organization. Retrieved from http://www.who.int/iris/handle/10665/38994

World Health Organisation. (n.d.). Health system governance: Overview. Retrieved from https://www.who.int/health-topics/health-systemsgovernance\#tab=tab_1

World Health Organization. (1999). Reduction of maternal mortality : a joint WHO/UNFPA/UNICEF/World Bank statement. Geneva. Retrieved from https://apps.who.int/iris/handle/10665/42191

World Health Organization. (2004). Making pregnancy safer: the critical role of the skilled attendant A joint statement by WHO, ICM and FIGO. Geneva: World Health Organization.

World Health Organization. (2010). The World Health Report: Health Systems Financing: The Path to Universal Coverage. Geneva, Switzerland.

World Health Organization. (2014). Trends in maternal mortality: 1990 to 2013. Estimates by WHO, UNICEF, UNFPA, The World Bank and the United Nations Population Division. Geneva, Switzerland. https://doi.org/https://apps.who.int/iris/handle/10665/112682

World Health Organization. (2015). Health in 2015: from MDGs, Millennium Development Goals to SDGs, Sustainable Development Goals. Geneva: WHO.

World Health Organization. (2016). WORLD HEALTH STATISTICS - MONITORING HEALTH FOR THE SDGs. World Health Organization, 1.121. https://doi.org/10.1017/CBO9781107415324.004

World Health Organization. (2019). Trends in Maternal Mortality 2000 to 2017: Estimates by WHO, UNICEF, UNFPA, World Bank Group and the United Nations Population Division. The Lancet (Vol. 390). Geneva, Switzerland. https://doi.org/10.1016/s01406736(17)33167-7

World Health Organization \& The World Bank. (2015). TRACKING UNIVERSAL HEALTH COVERAGE: First Global Monitoring Report. Geneva. Retrieved from https://apps.who.int/iris/bitstream/handle/10665/174536/9789241564977_eng.pdf?sequence=1
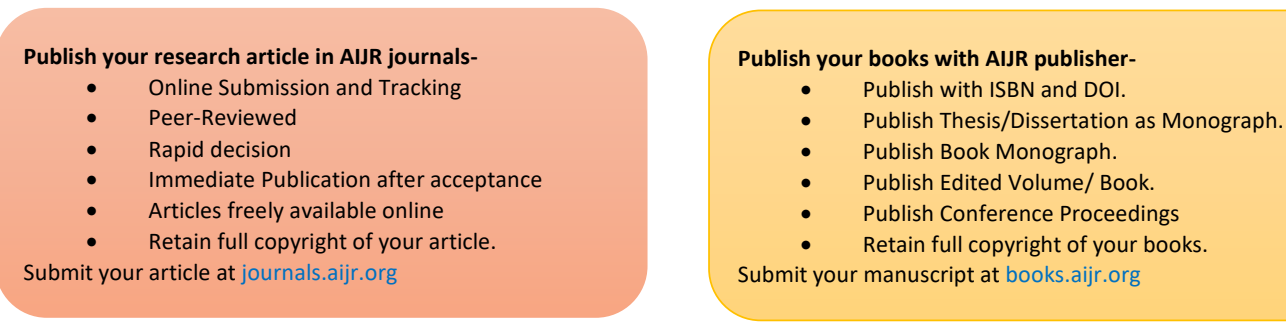


\section{Appendix 1: Included Studies}

Saaka M Akuamoah-Boateng J., 2020

Asante-Sarpong et al., 2016

Sakeah et al., 2014

Atinga, R. A., Baku, A. A. \& Adongo, P. B., 2014

Gudu W \& Addo B., 2017

Ganle JK Kombet ML Baatiema L., 2019

Amoako Johnson F, 2016

Browne JL et al., 2016

Khan SM \& Singh K., 2016

Crissman et al., 2017

Adatara P, Strumpher J, Ricks E., 2019

Cofie et al., 2015

Saah et al., 2019

Avortri GS Modiba LM., 2018

Peprah et al., 2018

Gudu W \& Addo B., 2017

Dankwah E et al., 2019

Dickson KS et al., 2016

Asamoah BO Agardh A Cromley EK., 2014

Ganle, 2015

Dotse-Gborgbortsi et al., 2019

Ameyaw et al., 2016

Amu, H. \& Sekyi, D. K., 2018

Cofie et al., 2018

\section{APPENDIX 2: Search Strategy}

CINAHL Plus with Full Text (EBSCO)

Ebscohost

http://search.ebscohost.com/login.aspx?direct $=$ true $\& d b=a 9 h \& d b=10 h \& d b=b t h \& d b=e h h \& d b=8$ gh $\& d b$ $=\mathrm{hxh} \& \mathrm{db}=\mathrm{hch} \& \mathrm{db}=\mathrm{lih} \& \mathrm{db}=\mathrm{f} 5 \mathrm{~h} \& \mathrm{db}=\mathrm{mnh} \& \mathrm{db}=\mathrm{nfh} \& \mathrm{db}=\mathrm{b} w h \& \mathrm{db}=\mathrm{rlh} \& \mathrm{db}=\mathrm{e} 864 \mathrm{sww} \&$ bquery $=$ utilisa tion + of + skilled + delivery + in + Ghana\&cli $0=$ RV\&clv0 $=$ Y\&cli1 $=$ DT1\&clv1 $=201001-$

202012\&dli0 $=\mathrm{LA} 10 \& \mathrm{dlv} 0=$ English $\& \mathrm{dld} 0=\mathrm{ehh} \& \mathrm{dli} 1=\mathrm{AA} 1 \& \mathrm{dlv} 1=\mathrm{Y} \& \mathrm{dld} 1=\mathrm{mnh} \& \mathrm{dli} 2=\mathrm{LA} 1 \& \mathrm{dlv} 2=\mathrm{Y} \&$ $\mathrm{dld} 2=\mathrm{mnh} \& \mathrm{dli} 3=\mathrm{EB} 1 \& \mathrm{dlv} 3=\mathrm{Y} \& \mathrm{dld} 3=\mathrm{mnh} \& \mathrm{dli} 4=\mathrm{PT} 2 \& \mathrm{dl} 4=\mathrm{Y} \& \mathrm{dld} 4=\mathrm{mnh} \& \mathrm{dli} 5=\mathrm{CT} 2 \& \mathrm{dl} 55=\mathrm{Y} \& \mathrm{dld}$ $5=$ mnh\&type $=0 \&$ searchMode $=$ Standard $\&$ site $=$ ehost-live

PubMed Central

(utilisation[All Fields] AND skilled[All Fields] AND ("delivery, obstetric"[MeSH Terms] OR ("delivery"[All Fields] AND "obstetric"[All Fields]) OR "obstetric delivery"[All Fields] OR "delivery"[All Fields]) AND ("ghana"[MeSH Terms] OR "ghana"[All Fields])) AND ("2010/01/01"[PubDate] : "2020/12/31"[PubDate])

Search date: 02/06/21

Medical Subject Headings (MESH) term: "utilization of skilled delivery in Ghana"

Date: $01 / 01 / 2010$ - 31/12/2020

Language: English 